\title{
Cardiovascular System Response to Chronic Exposure to Emissions from Gas Turbines Power Plants
}

\author{
C. D. Ekpruke*, V. I. Iyawe \\ Department of Physiology, School of Basic Medical Sciences, University of Benin, Benin-City, Edo State, Nigeria \\ Email: ^damilola.ekpruke@uniben.edu
}

How to cite this paper: Ekpruke, C.D. and Iyawe, V.I. (2020) Cardiovascular System Response to Chronic Exposure to Emissions from Gas Turbines Power Plants. World Journal of Cardiovascular Diseases, 10 , 208-224.

https://doi.org/10.4236/wjcd.2020.104020

Received: December 30, 2019

Accepted: April 23, 2020

Published: April 26, 2020

Copyright $\odot 2020$ by author(s) and Scientific Research Publishing Inc. This work is licensed under the Creative Commons Attribution International License (CC BY 4.0).

http://creativecommons.org/licenses/by/4.0/

\begin{abstract}
Objectives: Heart Rate and Blood Pressure have been reported to be susceptible to the effects of air pollution. Effect of emissions from gas turbine power station among workers is relatively unexplored. Therefore, this study aimed at assessing the effect of emissions from gas turbines on cardiovascular functions and C-reactive protein level in workers of power generating stations. Methodology: 440 individuals made up of 228 workers of gas-fired power plant stations and 212 non-power generating station workers volunteered for this study. A detailed questionnaire was carefully filled by volunteers and anthropometric data measured and recorded. Blood pressure, heart rate and C-reactive protein level (CRP) were measured using standard laboratory techniques in all subjects. Results were presented as Mean \pm Standard Error of Mean (SEM) and appropriate analysis was done using Independent student's t-test and Analysis of Variance (ANOVA). P-value $<0.05$ was taken as statistically significant. Results: Result showed increased systolic blood pressure (SBP), $142.45 \pm 8.87 \mathrm{mmHg}$ of test subjects compared to that of the control $(\mathrm{P}<0.05)$ which was $121.32 \pm 2.25 \mathrm{mmHg}$. However, there was no statistically significant difference in the Diastolic Blood Pressure (DBP) of the test and control groups. The Pulse Rate (PR) increased significantly in the test group (89.00 $\pm 0.02 \mathrm{bpm})$ when compared to that of the control group (74.34 $\pm 1.23 \mathrm{bpm})$. There was also an elevated plasma level of CRP, $6.69 \pm 0.03$ $\mathrm{mg} / \mathrm{L}$ in the test group compared to the control $(\mathrm{P}<0.05)$ which was $2.15 \pm$ $0.01 \mathrm{mg} / \mathrm{L}$. Conclusion: Exposure to gas emission from natural gas-fired power plants on workers of power generating stations increased SBP, PR and C-reactive Protein level.
\end{abstract}

\section{Keywords}

Emissions, Heart Rate, Systolic Blood Pressure, Diastolic Blood Pressure, Gas 
Turbines

\section{Introduction}

Air pollution has been reported by many researchers to be strongly associated with morbidity and mortality due to cardio-respiratory disease [1] [2]. Blood pressure and heart rate are susceptible to the effects of air pollution [3] [4] [5]. Prolonged exposure to particulate matter smaller than $2.5 \mu \mathrm{m}\left(\mathrm{PM}_{2.5}\right)$ causes $9 \%$ increase in cardiopulmonary mortality [6]. Mortality due to ischemic heart disease, dysrhythmias, heart failure and cardiac arrest was strongly associated with PM, Sulphur and sulphur dioxide exposure. People living by major road have been reported to have an increased cardiopulmonary mortality risk. A linear relationship may exist between particle exposure and mortality [7] [8]. There is no known threshold with which PM has not exerted any negative effect on the cardiopulmonary system even though this has not been established for other pollutants. In terms of cardiovascular diseases, studies have focused on potential effects of pollutants on inflammatory blood markers such as C-reactive Protein and Autonomic Nervous System [9] [10]. Even though there is a clear evidence of the association between air pollution and cardiovascular diseases, many studies have used populations such as the elderly, children and high-level pollutant-exposed individuals; this study used healthy workers of power generating stations using natural gas-fired power plants which have been assumed to produce fewer emissions with no negative health implications. Hence this study was aimed at assessing the effect of exposure to emissions from gas turbine power plants on cardiovascular system parameters and C-reactive Protein of workers of power generating stations.

\section{Materials and Methods}

\section{Study Design and Area}

This was a cross-sectional descriptive study conducted in Gas Turbine Power Plant in the South-South region of Nigeria from 2015 to 2016.

\section{Ethical committee approval}

Ethical committee approval was obtained from the Ethical committee of the Ministry of Health, Edo State before the commencement of this work.

Written, informed and Verbal consent was obtained from all volunteers.

\section{Sample Size}

The sample size was determined using the formula:

$$
\frac{(Z-\text { score })^{2} * \text { Standard Deviation } *(1-\text { Standard Deviation })}{(\text { Margin of error })^{2}}
$$

for unknown sample size a method previously described by Scott, (2013). Where $Z$-score for $95 \%$ confidence interval is 1.96 , standard Deviation was taken as 0.5 while the margin of error was taken as 0.05 . 


$$
\begin{aligned}
\text { sample size } & =\left((1.96)^{2} \times 0.5(0.5)\right) /(0.05)^{2} \\
\text { Hence, } \quad & =384.16 \\
& \approx 384
\end{aligned}
$$

The sample size was increased using $14 \%$ attrition rate, which made the sample size 440 to be able to cover up for any unforeseen causes that may lead to a decrease in the calculated population size. This implied that 440 volunteers participated in the study. This was divided into two groups:

1) Control Group $(\mathrm{N}=212:$ Males $=82$ and Females $=130)$.

2) Study/Experimental Group $(\mathrm{N}=228:$ Males $=129$ and Females $=99)$.

A total number of 440 volunteers made up of 228 power generating station workers (test group) and 212 non-power generating station workers (control group) including males and females participated in this study.

They were further divided into years of exposure these include:

1) those that have spent $1-5$ years in the company $(\mathrm{N}=103$ : Males $=55 ; \mathrm{Fe}-$ males $=48$ ).

2) those that have spent $6-10$ years in the company $(\mathrm{N}=73$ : Males $=40$; Females $=33$ ).

3) those that have spent more than 10 years in the company $(\mathrm{N}=52$ : Males $=$ 34; Females $=18$ ).

They were also divided into different groups based on areas of work in the company.

1) Those working directly in the power plant $(\mathrm{N}=82$ : Males $=57$; Females $=$ 25).

2) Those working in the offices $(\mathrm{N}=76$ : Males $=42$; Females $=34)$.

3) Others: This category included all the people working in the company but is neither directly in the power plant nor the offices. Such as the security men, cleaners, caterers and clinic workers $(\mathrm{N}=70$ : Males $=30$; Females $=40)$.

\section{Inclusion and Exclusion criteria for both the Control and Test Groups Inclusion Criteria}

Those in the test group were volunteers, Age 20 - 60 years, have no cardiovascular disease with no known family history of any cardiovascular disease, have not undergone any major surgery in the past three years and have been working in a gas turbine power plant for more than a year while those in the control group have never worked in a gas-turbine power plant or stay near the station.

\section{Exclusion Criteria}

While volunteers, workers of gas-turbine power generating stations and control group with a history of smoking or tobacco chewers, family history of allergy or any cardiovascular disease were excluded from the study.

\section{Questionnaire}

Detailed questionnaire (Appendix 1) was completed by each subjects requesting information about lifetime occupational and environmental exposure to air pollution, tobacco-smoking, medical and surgical history. Standard Respi- 
ratory symptoms questionnaire was based on that described by the Medical Research Council (MRC) (1960).

\section{Measurement of Anthropometric Parameter}

Weight of the control and test subjects were recorded in kilograms (kg) using Avery Scale (Avery Berkel 2003 model, UK) while the height of volunteers was recorded in metres $(\mathrm{m})$ using a stadiometer.

\section{Measurement of Cardiovascular System Parameters}

Cardiovascular Parameters investigated include Systolic Blood Pressure (SBP), Diastolic Blood Pressure (DBP), Pulse pressure (PP) and Pulse Rate (PR). SBP and DBP were measured in the control and test subjects using the Auscultatory method with an Accuson Mercury Sphygmomanometer (2009) on the brachial artery.

PP was calculated using the formula: SBP-DBP

$\mathrm{PR}$ was measured using digital finger pulse oximeter named $\mathrm{O}_{2}$-easy pulse oximeter manufactured by CA.MI. Sri-Pilastro (PR) Italy. This was taken using the left index finger of the control and test subjects.

\section{Estimation of C-reactive Protein Level}

Following the aseptic procedure, $2 \mathrm{ml}$ of blood was collected in a plain bottle for CRP level estimation in the control and test subjects using enzyme-linked immunosorbent assays (ELISA) and assayed based on the principle described by [11].

\section{Statistical Analysis}

Results were presented as Mean \pm Standard Error of Mean (SEM) using Microsoft excel, 2010 and statistical package for social sciences (SPSS) 20. Appropriate analyses were done using Independent student's t-test, Analysis of Variance (ANOVA) and Pearson correlation. P-value $<0.05$ was taken as statistically significant.

\section{Result}

\section{Changes in Blood pressure}

Cardiovascular system parameters such as Systolic Blood Pressure (SBP), Diastolic Blood Pressure (DBP), Pulse Pressure (PP) and Pulse Rate (PR) values in the control and experimental groups are shown in Figures 1-8.

\section{Changes in Systolic Blood Pressure (SBP)}

The value of SBP (Figure 1 \& Figure 2) in the experimental group was statistically significantly higher than that of the control group at $\mathrm{P}<0.05$ in both male and female subjects. This value increased significantly with an increase in years of exposure irrespective of the area of work in the company at $\mathrm{P}<0.05$.

Changes in Diastolic Blood Pressure (DBP)

DBP (Figure 3 \& Figure 4) was not statistically significantly different from that of the control group at $\mathrm{P}<0.05$ based on years of exposure or areas of work in the company.

Changes in Pulse Pressure (PP) 


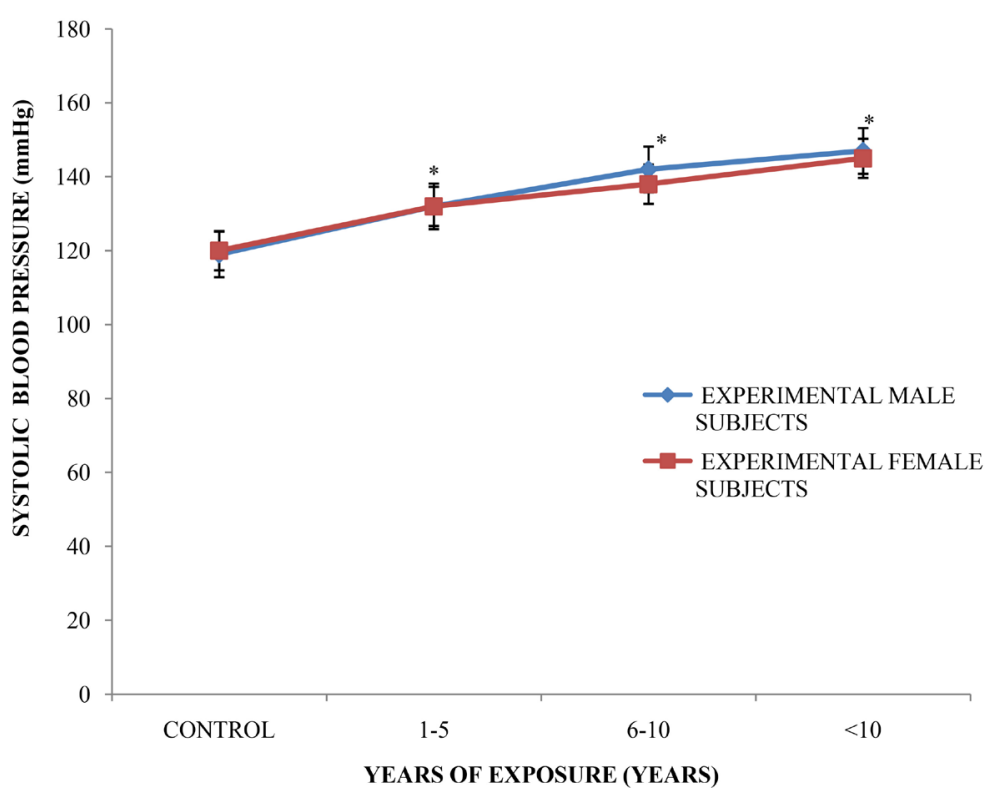

Figure 1. Showing the SBP in the experimental subjects based on years of exposure. $n=$ 440 ; mean \pm SEM. SBP increased with an increase in years of exposure $\mathrm{P}<0.05$.

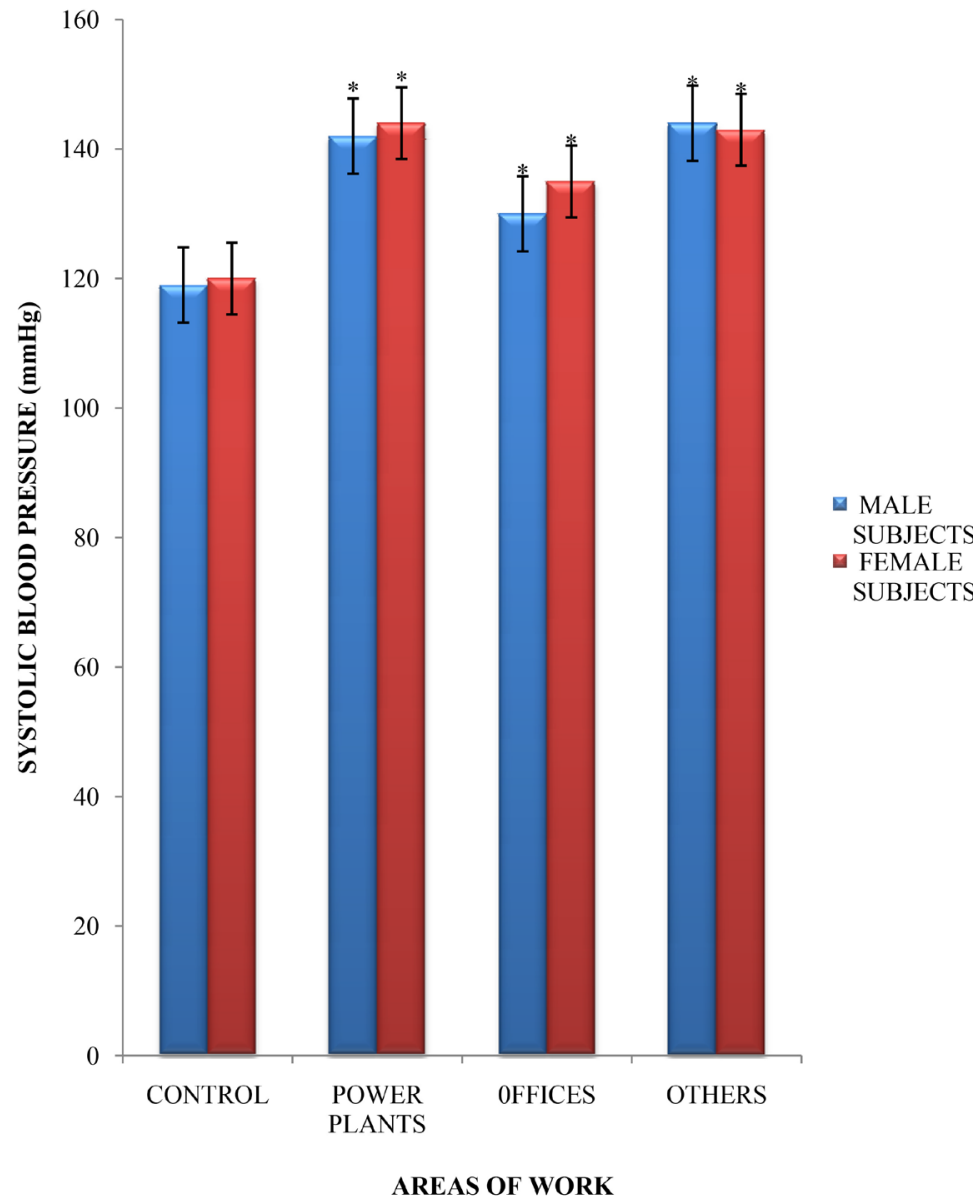

Figure 2. Showing the SBP in the experimental subjects based on different areas of work in the company $n=440$; mean \pm SEM. SBP increased significantly irrespective of areas of work in the company $\mathrm{P}<0.05$. 


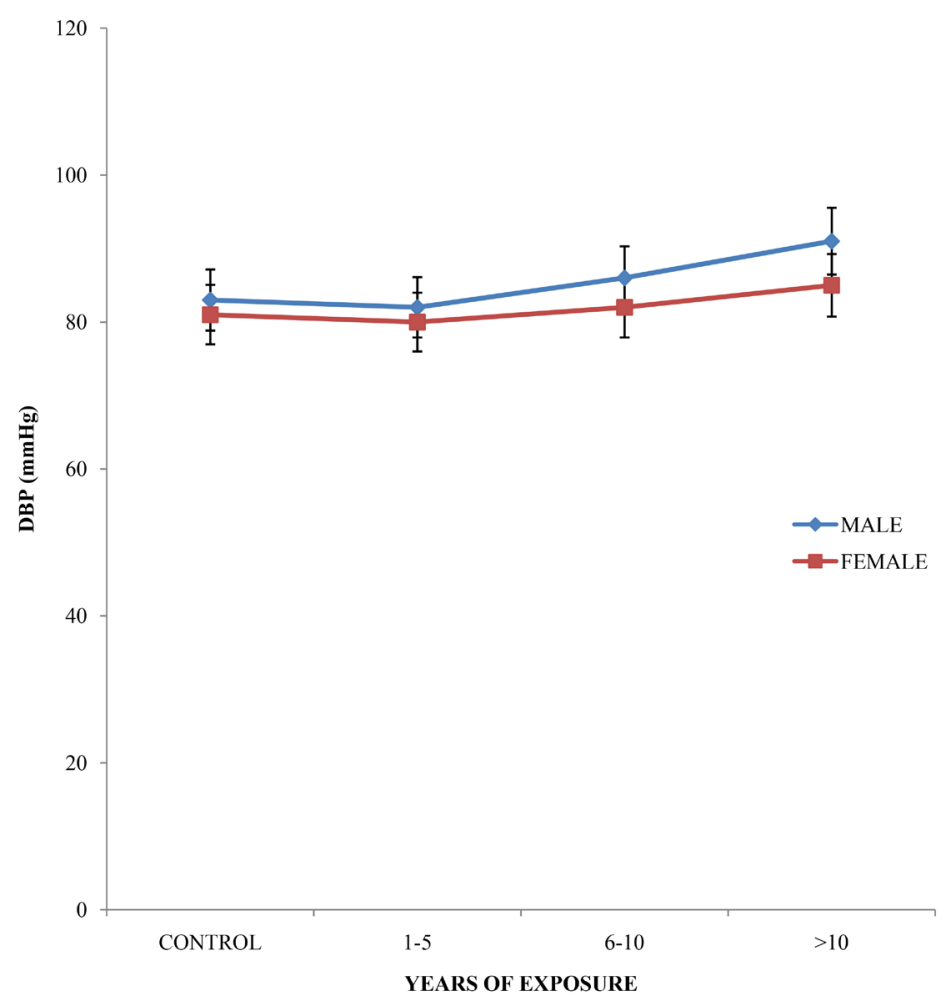

Figure 3. Showing the DBP in the experimental subjects based on years of exposure $\mathrm{n}=$ 440 ; mean \pm SEM. DBP value showed no statistically significant difference neither in years of exposure nor areas of work in the company $\mathrm{P}<0.05$.

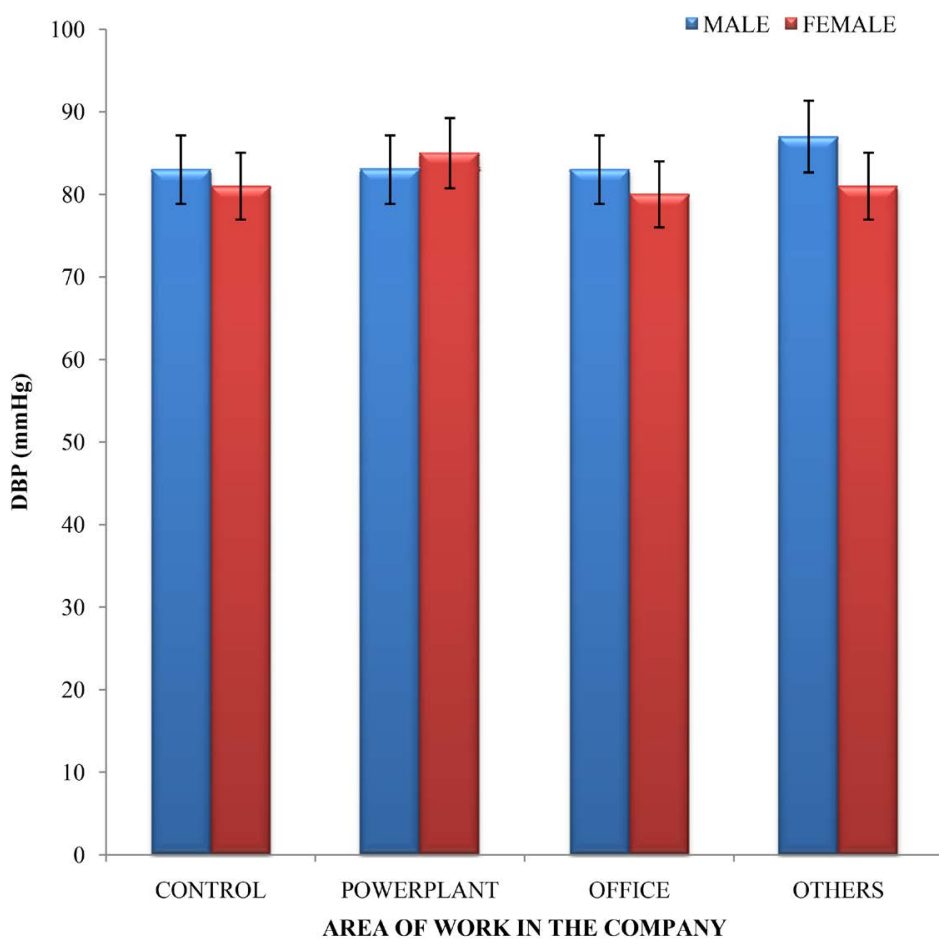

Figure 4. Showing the DBP in the experimental subjects based on different areas of work in the company $n=440$; mean \pm SEM. DBP value showed no statistically significant difference in areas of work in the company $\mathrm{P}<0.05$. 


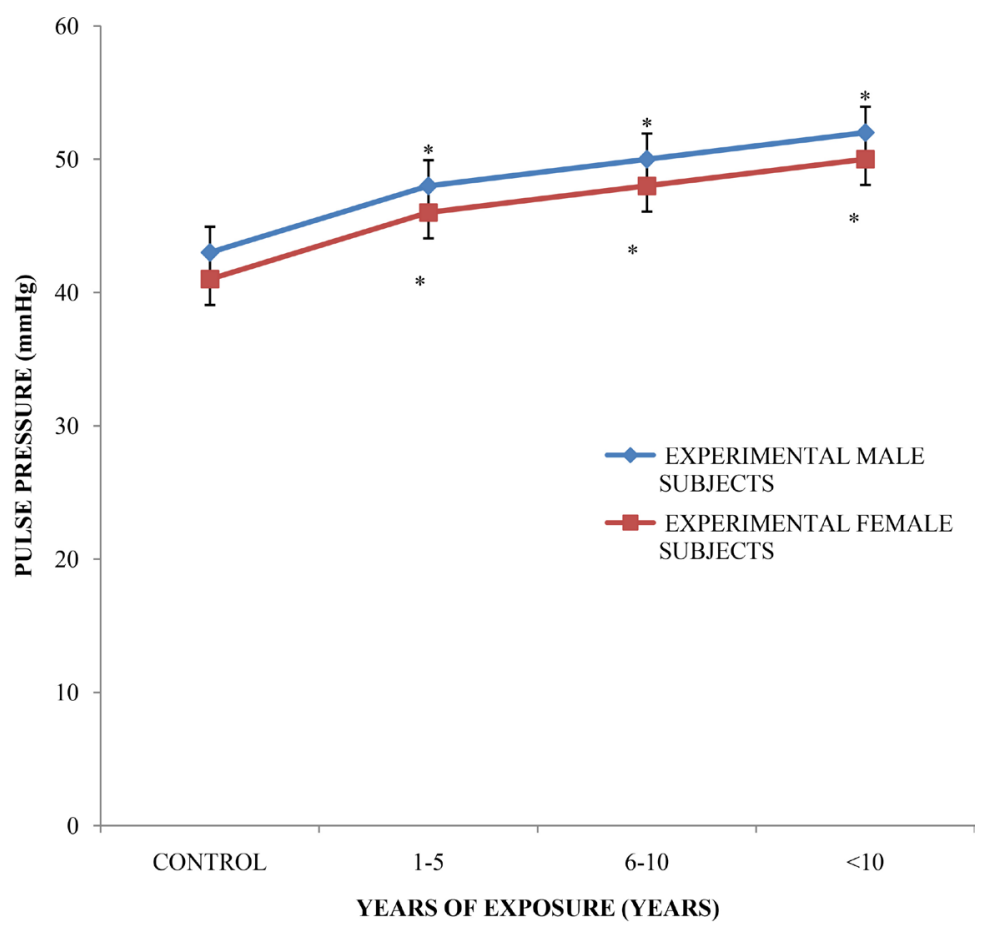

Figure 5. Showing PP in the experimental subjects $n=440$; mean \pm SEM. PP increases in the experimental male and female subjects with an increase in years of exposure compared to that of the control group at $\mathrm{P}<0.05$.

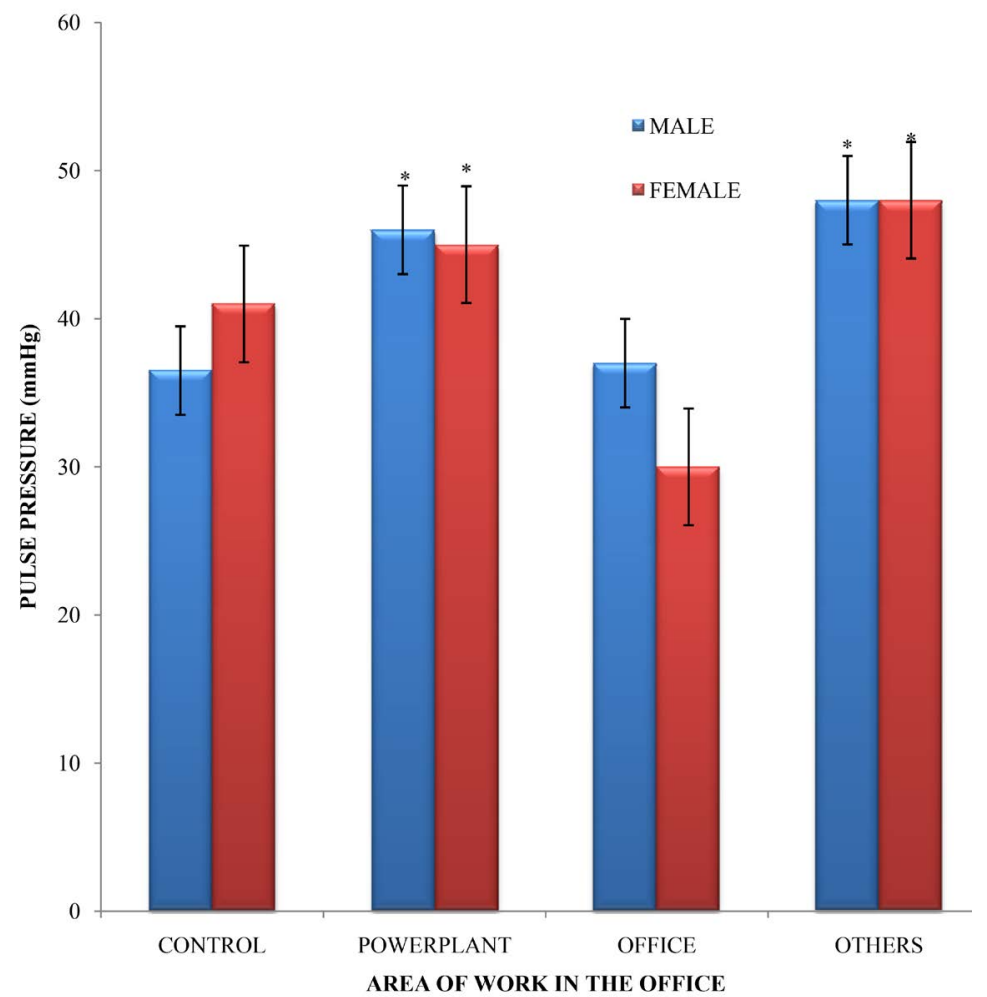

Figure 6. Showing PP in the experimental male and female subjects $n=440$; mean \pm SEM. PP increases in the experimental subjects based on different areas of work in the company but was not statistically different in those working in offices $\mathrm{p}<0.05$. 


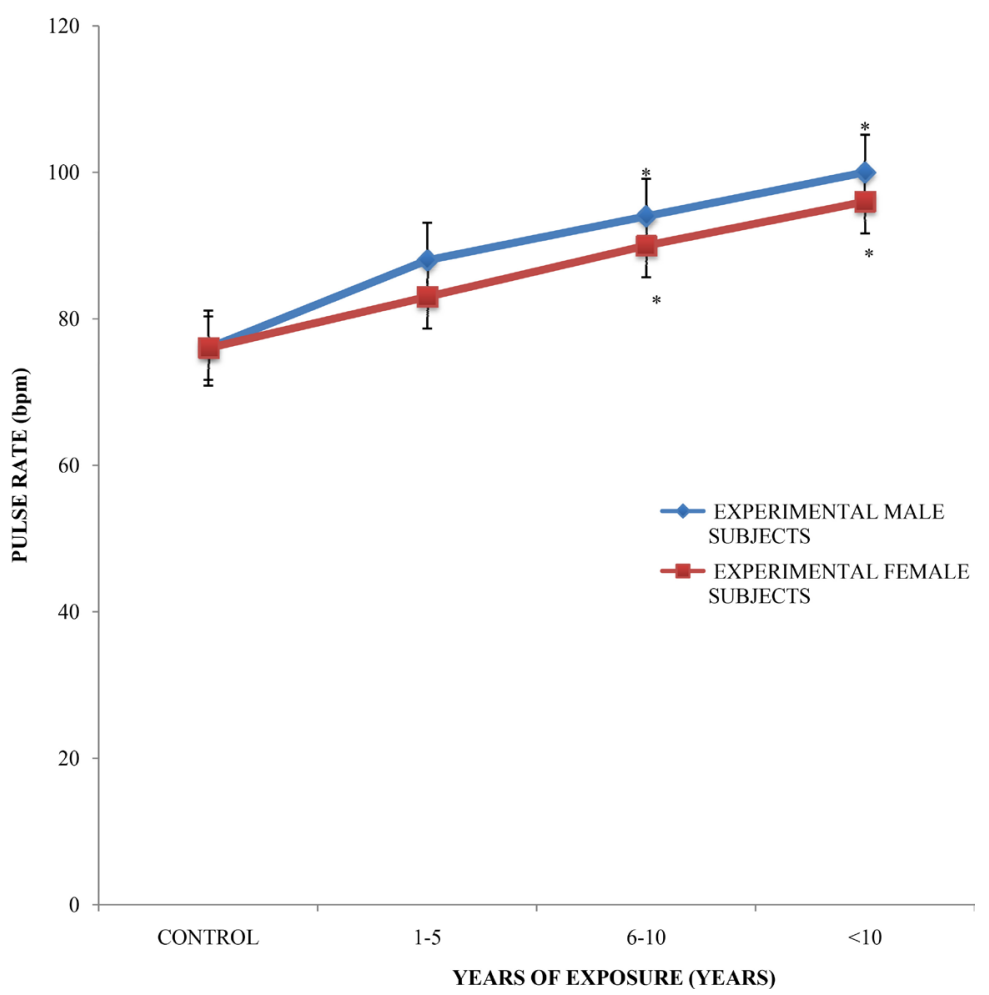

Figure 7. Showing PR in the experimental subjects $n=440$; mean \pm SEM. PR increased in the experimental subjects with an increase in years of exposure $\mathrm{P}<0.05$.

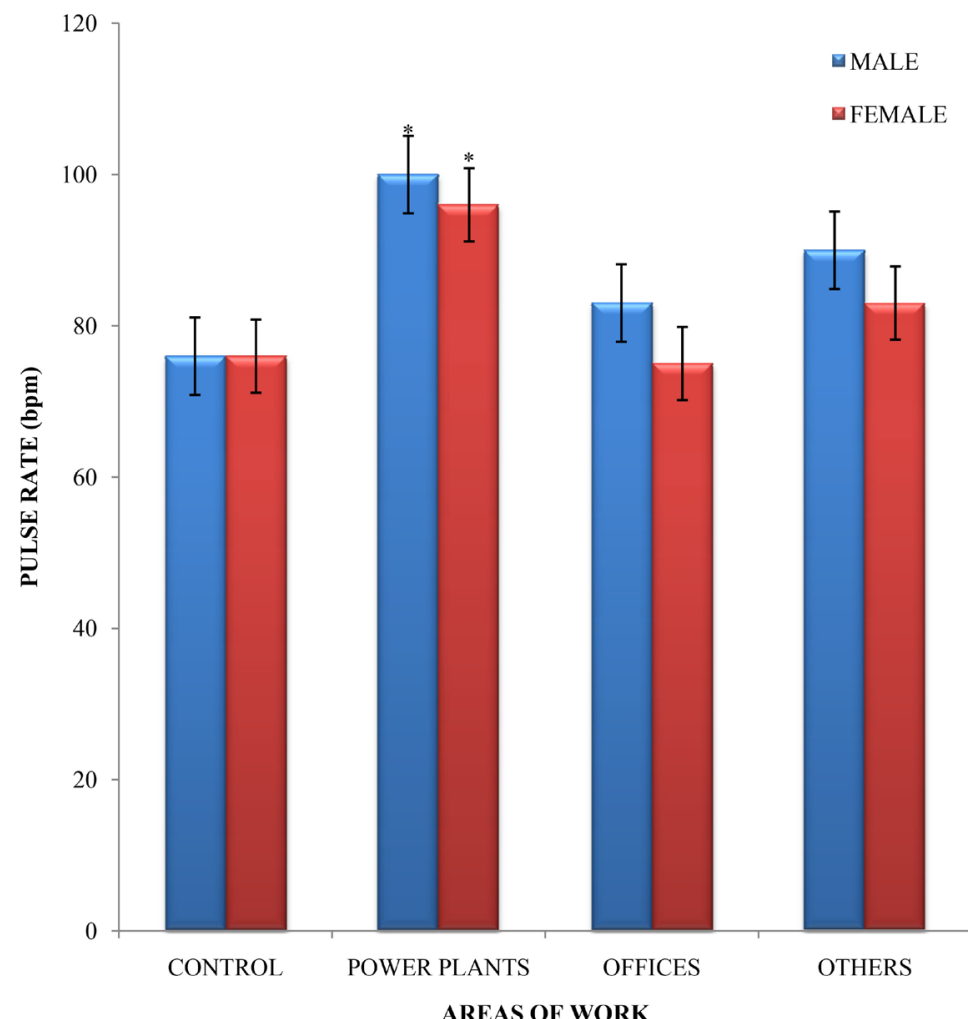

Figure 8. Showing PR in the experimental subjects $n=440$; mean \pm SEM. PR increases in the experimental subjects irrespective of areas of work in the company $\mathrm{P}<0.05$. 


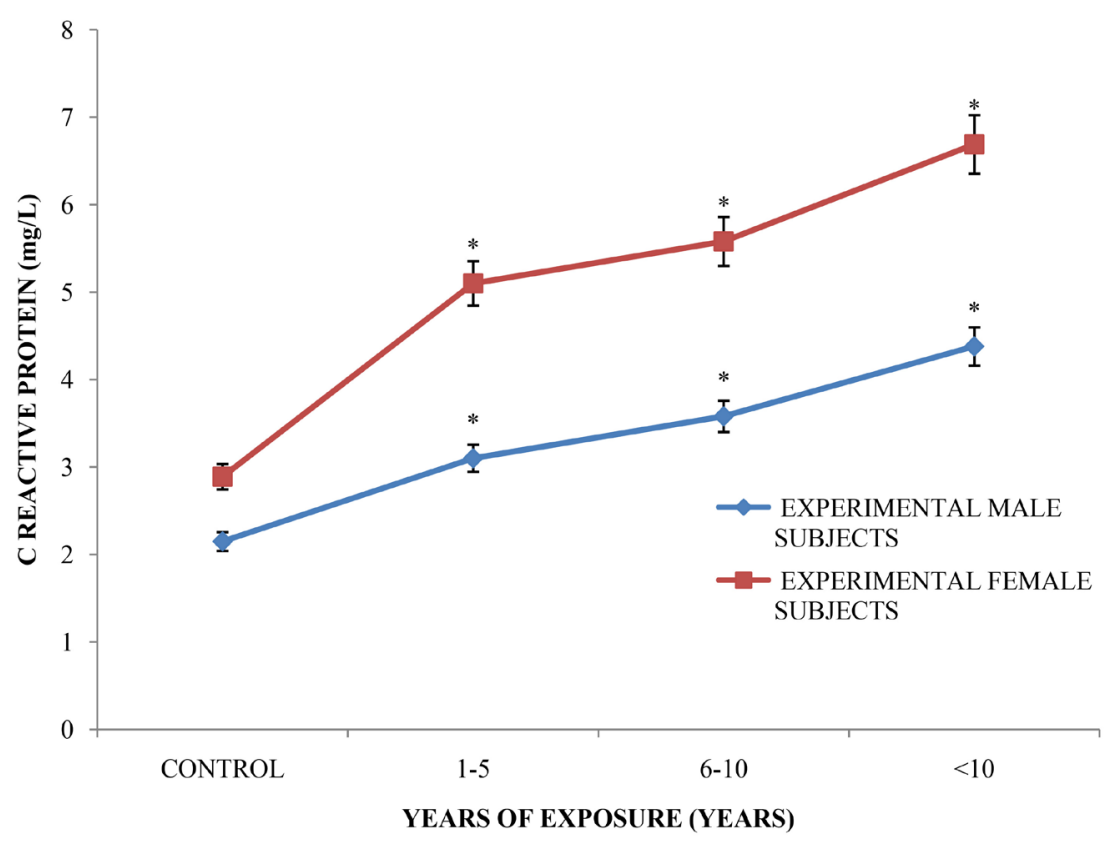

Figure 9. Showing CRP experimental subjects $n=440$; mean \pm SEM. CRP count increased significantly in the experimental subjects with an increase in years of exposure $\mathrm{P}$ $<0.05$.

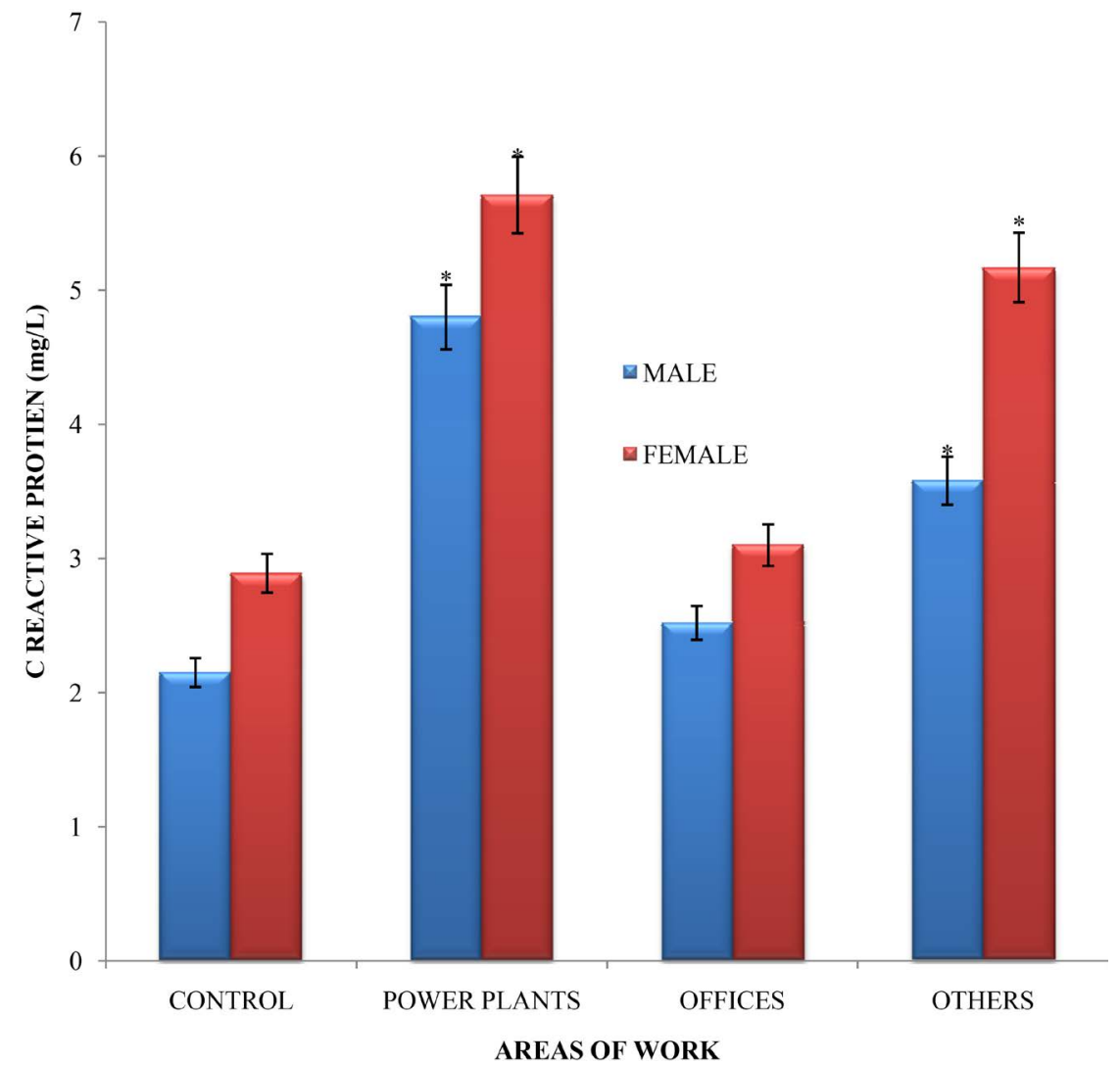

Figure 10. Showing CRP experimental subjects $n=440$; mean \pm SEM. CRP count increased significantly in the experimental subjects irrespective of areas of work in the company except in those working in office $\mathrm{P}<0.05$. 
The value of PP (Figure 5 \& Figure 6) was higher in the experimental group compared to that of the control group. This increased with years of exposure and in subjects working directly in the Power plants and other places in the company compared to that of the control group.

\section{Changes in Pulse Rate (PR)}

The value of PR (Figure 7 \& Figure 8) increased in the experimental subjects compared to that of the control group. Pulse Rate value was statistically significant only in male and female subjects that have spent more than 6 years in the company and are working directly in the power plant.

\section{Changes in C-Reactive Protein Level (CRP)}

The value of CRP was higher in the experimental group compared to that of the control group at $\mathrm{P}<0.05$ as shown in Figure 9 \& Figure 10. This also increased with years of exposure and in subjects working directly in the Power plants and around the company compared to that of the control group at $\mathrm{P}<$ 0.05 .

Table 1 showing some characteristics of subjects used in this study. Note: others included subjects working in other areas of the power generating stations.

\section{Discussion}

\section{Blood Pressure}

This study showed that emission from gas turbine Power Plants might affect cardiovascular system parameters such as Systolic Blood pressure (SBP), Diastolic Blood Pressure (DBP), Pulse Pressure (PP) and Heart rate (HR) in a group of healthy, non-smoking adults with a similar degree of education and socio-economic status working in gas turbine power generating stations. Results showed a statistically significant increase in SBP and PP as shown in Figure 1, Figure 2, Figure 5 and Figure 6 which worsen with an increase in years of

Table 1. Descriptive statistics of the study population.

\begin{tabular}{lcc}
\multicolumn{1}{c}{ Characteristics } & Control subjects ( $\mathbf{n}=)$ & Experimental subjects $(\mathbf{n}=)$ \\
\hline Age (years) & 33 & 35 \\
Sex & 82 & 129 \\
$\quad$ Male & 130 & 99 \\
$\quad$ Female & & \\
Duration of working hours in the test & - & 8 \\
environment (hours) & & \\
& - & 103 \\
Years of Exposure & - & 73 \\
1 - 5 & - & 52 \\
6 - 10 & & 83 \\
$<10$ & - & 76 \\
Areas of work in the test environment & - & 70 \\
Power plants & - & \\
Offices & & \\
Others & & \\
\hline
\end{tabular}


exposure irrespective of the area of work in the company. DBP, as shown in Figure 3 and Figure 4 was not statistically significantly different in the control and experimental groups. This was in agreement with the work of [12] who reported that Brachial artery vasoconstriction was observed after exposure to air pollutants leading to an increase in blood pressure. Also, [13] carried out research using healthy, non-elderly workers exposed to Particulate Matter $\left(\mathrm{PM}_{2.5}\right)$ and reported an increase in cardiovascular system parameters though the ambient concentration of $\mathrm{PM}_{2.5}$ was very high. The findings in this study were however not in agreement with the study of [14], who reported that negative association between particles and blood pressure was observed in a cardiac patient exposed to air pollution even though he explained that his result may be due to the effect of drug intake on autonomic control of the heart.

Physiologically, the control of the cardiovascular system parameters such as blood pressure is permanently under the influence of Autonomic Nervous System which is predominantly, the parasympathetic nervous system. Factors such as mental stress, caused by occupational exposure to air pollution may alter the normal control process by decreasing the influence of parasympathetic and increasing sympathetic tone causing vasoconstriction which may lead to increase in blood pressure and heart rate [15] [16]. Another possible cause of vasoconstriction is the acute increase in the release of vascular endothelin [12] [14]. These pathways may likely be the mechanism through which emissions from gas-turbine power plants causes vasoconstriction leading to an increase in systolic blood pressure and pulse pressure. However, DBP remained unchanged both in the control and experimental groups, this supports the recent fact that elevated SBP and PP are a high-risk indicator of heart attack, heart failure or stroke while DBP is inversely related to cardiovascular risk [17].

\section{Heart Rate}

Heart rate has been reported to be used as a risk marker for arrhythmia and sudden death [18] [19]. It is usually affected by environmental changes such as exposure to air pollutants occupationally, this causes an imbalance of the autonomic system and may lose the capacity to adapt to several stimuli that occur daily [20]. In this study, increase in heart rate and strong positive association between heart rate and pollutants were observed which agreed with the report that increased risks for both myocardial infarction [21] and discharges in patients with implanted cardioverter defibrillation associated with an increase in Particulate and gaseous pollutants [21]. The reason may be caused by an imbalance of Autonomic Nervous System caused by exposure to emissions from natural-gas-fired power plants leading to decrease of parasympathetic activity followed by an increased sympathetic tone. However, [16] report also supported the evidence that air pollutants may induce increased myocardial susceptibility causing ischaemic heart diseases this may still be explained by artery constriction or blood pressure increase [12] and elevated level of CRP which are a well-known risk factor of coronary heart disease [19]. 


\section{C-reactive Protein}

This study showed an elevated level of the inflammatory marker, CRP when compared to that of the control group as shown in Figure 9 and Figure 10. This finding aligned with the report of [22] who reported that a stronger association between CRP level and increased Heart rate was observed in a group of individuals exposed to short-term air pollution. Others have also reported a relationship between elevated markers of systemic inflammation and increased heart rate both in the cardiac patient [23] [24] and healthy individuals [25] [26]. Air pollution over the years has been associated with increased inflammatory markers including CRP [27] [28] [29] even though the mechanism involved is not well elucidated. However, many researchers including Framingham study [30] have used baseline measures of CRP as predictors of long term adverse cardiac outcome.

\section{Limitations of the study}

1) The study did not capture power generating worker that had less than a year exposure.

2) Blood gas analysis was not carried out to ascertain the presence of pollutant measured in the blood.

\section{Conclusion}

The result showed that exposure to emissions from the gas-turbine power plant has adverse effects on the cardiovascular system evidenced by increased SBP, PP, $\mathrm{HR}$ and CRP. Therefore, further investigations are required in a similar research area rather than assume that a natural-gas-fired plant produces fewer emissions with no negative effect on human health.

\section{Conflicts of Interest}

The authors declare no conflicts of interest regarding the publication of this paper.

\section{References}

[1] Lin, C.A., Pereira, L.A.M. and Conceicao, G.M.S. (2003) Association between Air Pollution and Ischemic Cardiovascular Emergency Room Visits. Environmental Research, 57, 57-63. https://doi.org/10.1016/S0013-9351(02)00054-3

[2] Saldiva, P.H., Clarke, R.W. and Coull, B.A. (2002) Lung Inflammation Induced by Concentrated Ambient Air Particles Is Related to Particle Composition. The American Journal of Respiratory and Critical Care Medicine, 165, 1610-1617. https://doi.org/10.1164/rccm.2106102

[3] Magari, S.R., Hauser, R. and Schwartz, J. (2001) Association of Heart Rate Variability with Occupational and Environmental Exposure to Particulate Air Pollution. Circulation, 104, 986-991. https://doi.org/10.1161/hc3401.095038

[4] Godleski, J.J., Verrier, R.L. and Koutrakis, P. (2000) Mechanism of Morbidity and Mortality from Exposure to Ambient Air Particles. Research Report (Health Effects Institute), 91, 5-88. 
[5] Gold, D.R., Litonjua, A. and Schwartz, J. (2000) Ambient Pollution and Heart Rate Variability. Circulation, 101, 1267-1273. https://doi.org/10.1161/01.CIR.101.11.1267

[6] Pope, C.A. III, Burnett, R.T. and Thurston, G.D. (2004) Cardiovascular Mortality and Long-Term Exposure to Particulate Air Pollution: Epidemiological Evidence of General Pathophysiological Pathways of Disease. Circulation, 109, 71-77. https://doi.org/10.1161/01.CIR.0000108927.80044.7F

[7] Dockery, D.W., Pope, C.A. III and Xu, X. (1993) An Association between Air Pollution and Mortality in Six US Cities. The New England Journal of Medicine, 329, 1753-1759. https://doi.org/10.1056/NEJM199312093292401

[8] Daniels, M.J., Dominici, F., Samet, J.M. and Zeger, S. (2000) Estimating Particulate Matter-Mortality Dose-Response Curves and Threshold Levels: An Analysis of Daily Time-Series for the 20 Largest US Cities. American Journal of Epidemiology, 152, 397-406. https://doi.org/10.1093/aje/152.5.397

[9] Seaton, A., MacNee, W., Donaldson, K. and Godden, D. (1995) Particulate Air Pollution and Acute Health Effects. The Lancet, 345, 176-178. https://doi.org/10.1016/S0140-6736(95)90173-6

[10] Stone, P.H. and Godleski, J.J. (1999) First Steps toward Understanding the Pathophysiologic Link between Air Pollution and Cardiac Mortality. American Heart Journal, 138, 804-807. https://doi.org/10.1016/S0002-8703(99)70002-5

[11] Votila, M., Ruslanti, E. and Engull, E. (1981) Two-Site Sandwich Enzyme Immunoassay with Monoclonal Antibodies to Human Alpha-Fetoprotein. The Journal of Immunological Methods, 42, 11-15. https://doi.org/10.1016/0022-1759(81)90219-2

[12] Brook, R.D., Brook, J.R. and Urch, B. (2002) Inhalation of Fine Particulate Air Pollution and Ozone Causes Acute Arterial Vasoconstriction in Healthy Adults. Circulation, 105, 1534-1536. https://doi.org/10.1161/01.CIR.0000013838.94747.64

[13] Pope, C.A. III, Dockery, D.W. and Kanner, R.E. (1999) Oxygen Saturation, Pulse Rate, and Particulate Air Pollution. A Daily Time-Series Panel Study. The American Journal of Respiratory and Critical Care Medicine, 159, 365-372. https://doi.org/10.1164/ajrccm.159.2.9702103

[14] Ibald-Mulli, A., Stieber, J. and Wichmann, H.-E.A. (2001) Effects of Air Pollution on Blood Pressure: A Population-Based Approach. American Journal of Public Health, 91, 571-577. https://doi.org/10.2105/AJPH.91.4.571

[15] Grassi, G. (1998) Role of the Sympathetic Nervous System in Human Hypertension. Journal of Hypertension, 16, 1979-1987. https://doi.org/10.1097/00004872-199816121-00019

[16] Pekkanen, J., Peters, A. and Hoek, G. (2002) Particulate Air Pollution and Risk of ST-Segment Depression during Repeated Submaximal Exercise Tests among Subjects with Coronary Heart Disease. Circulation, 106, 933-938. https://doi.org/10.1161/01.CIR.0000027561.41736.3C

[17] Yusuf, S., Sleight, P., Pogue, J., Bosch, J., Davies, R. and Dagenais, G. (2000) Effects of an Angiotensin-Converting-Enzyme Inhibitor, Ramipril, on Cardiovascular Events in High-Risk Patients: The Heart Outcomes Prevention Evaluation Study Investigators. The New England Journal of Medicine, 342, 145-153. https://doi.org/10.1056/NEJM200001203420301

[18] Huikuri, H.V., Castellanos, A. and Myerburg, R.J. (2001) Sudden Death Due to Cardiac Arrhythmias. The New England Journal of Medicine, 345, 1473-1482. https://doi.org/10.1056/NEJMra000650

[19] Van den Hoogen, P.C.W., Feskens, E.J.M. and Nagelkerke, N.J.D. (2000) The Relation between Blood Pressure and Mortality Due to Coronary Heart Disease among 
Men in Different Parts of the World. The New England Journal of Medicine, 342, 1-8. https://doi.org/10.1056/NEJM200001063420101

[20] Sandhu, R.S., Petroni, D.H. and George, W.J. (2005) Ambient Particulate Matter, C-Reactive Protein, and Coronary Artery Disease. Inhalation Toxicology, 17, 409-413. https://doi.org/10.1080/08958370590929538

[21] Peters, A., Liu, E. and Verrier, R.L. (2000) Air Pollution and Incidence of Cardiac Arrhythmia. Epidemiology, 11, 11-17. https://doi.org/10.1097/00001648-200001000-00005

[22] Luttmann-Gibson, H., Suh, H.H., Coull, B.A., Dockery, D.W., Sarnat, S.E., Schwartz, J., Stone, P.H. and Gold, D.R. (2010) Systemic Inflammation, Heart Rate Variability and Air Pollution in a Cohort of Senior Adults. Occupational and Environmental Medicine, 67, 625-630. https://doi.org/10.1136/oem.2009.050625

[23] Hamaad, A., Sosin, M. and Blann, A.D. (2005) Markers of Inflammation in Acute Coronary Syndromes: Association with Increased Heart Rate and Reductions in Heart Rate Variability. Clinical Cardiology, 28, 570-576.

https://doi.org/10.1002/clc.4960281207

[24] Madsen, T., Christensen, J.H. and Toft, E. (2007) C-Reactive Protein Is Associated with Heart Rate Variability. Annals of Noninvasive Electrocardiology, 12, 216-222. https://doi.org/10.1111/j.1542-474X.2007.00164.x

[25] Sajadieh, A., Nielsen, O.W. and Rasmussen, V. (2004) Increased Heart Rate and Reduced Heart-Rate Variability Are Associated with Subclinical Inflammation in Middle-Aged and Elderly Subjects with No Apparent Heart Disease. European Heart Journal, 25, 363-370. https://doi.org/10.1016/j.ehj.2003.12.003

[26] Lampert, R., Bremner, J.D. and Su, S. (2008) Decreased Heart Rate Variability Is Associated with Higher Levels of Inflammation in Middle-Aged Men. American Heart Journal, 156, 759,e1-7. https://doi.org/10.1016/j.ahj.2008.07.009

[27] Schwartz, J. (2001) Air Pollution and Blood Markers of Cardiovascular Risk. Environmental Health Perspectives, 109, 405-409. https://doi.org/10.1289/ehp.01109s3405

[28] Riediker, M., Cascio, W.E. and Griggs, T.R. (2004) Particulate Matter Exposure in Cars Is Associated with Cardiovascular Effects in Healthy Young Men. The American Journal of Respiratory and Critical Care Medicine, 169, 934-940. https://doi.org/10.1164/rccm.200310-1463OC

[29] Ruckerl, R., Ibald-Mulli, A. and Koenig, W. (2006) Air Pollution and Markers of Inflammation and Coagulation in Patients with Coronary Heart Disease. The American Journal of Respiratory and Critical Care Medicine, 173, 432-441. https://doi.org/10.1164/rccm.200507-1123OC

[30] Dhingra, R., Gona, P. and Nam, B.H. (2007) C-Reactive Protein, Inflammatory Conditions, and Cardiovascular Disease Risk. The American Journal of Medicine, 120, 1054-1062. https://doi.org/10.1016/j.amjmed.2007.08.037 


\section{Appendix 1}

ALL INFORMATION OBTAINED IN THE STUDY WILL BE KEPT CONFIDENTIAL AND USED FOR RESEARCH PURPOSE ONLY.

1) BIRTHDATE:

$$
\text { Month Day year }
$$

2) Place of Birth:

3) Sex: Male

Female

4) What is your marital status?

i) Single

ii) Married

iii) Widowed

iv) Separated/Divorced

5) What is the highest grade completed in school?

a) Primary

b) Secondary/college/Technical

c) Diploma

d) First Degree

e) Others pls specify

6) Height ..... . $\mathrm{cm}$

Weight .. $\mathrm{kg}$

7) Waist circumference ...........cm

8) Blood pressure: systolic ..............mmhg diastolic mmgh

9) Respiration per min.

10) Forced Vital Capacity (FVC)

11) Forced Expiratory Volume (FEV1)

12) peak expiratory flow rate

13) Oxygen saturation level

\section{AIRWAY SYMPTOMS AND HEALTH HISTORY}

Please kindly TICK yes or no if possible

1. Have you ever in the last 12 months experience a high or rough noisy breathing?

2. Have you ever experience breathlessness?

3. Does breathlessness happens only when you have cold or catarrh?

4. Have you ever in the last 12 months waked up in the middle of the night with chest tightness?

5. Have you ever in the last 12 months waked up with coughing?

6. Have you in the last 12 months had asthma attacks?

7. Do you at present use asthma medication, for example, inhaler, franol, Ventolin drugs e.t.c?

8. Have you ever, even when not having a cold or flu had sneezing or nose itching? 


\section{Continued}

9. Have you ever, even when not having a cold or flu had running nose?

10. Have you ever, even when not having a cold or flu had nose blockage?

11. Have you ever been told by a doctor that you have hypertension or high blood pressure?

12. Do you smoke?

13. Have you smoked this week?

14. Have you smoked in the last one or two months?

15. Have you smoked more than three months ago?

16. Do you take any form of alcohol?

17. Have you taken alcohol this week?

18. Have you taken alcohol in the last one or two months?

19 Have you taken alcohol more than three months ago?

\section{WORK-RELATED SYMPTOMS}

Please kindly TICK yes or no if possible

Do nasal symptoms trigger starts or worsen when you come into the working environment?

2 .

Do nasal symptoms trigger of or worsen when you enter the power plant or its environ

Do you have nasal symptoms improved during the weekend, when off or on leave?

4. Do you have eye symptoms at work such as tears coming out of your eyes?

5. Do you have eye symptoms at work such as itching?

6. Have you ever experience breathlessness at work?

7. Have you ever experienced chest tightness at work?

8. Have you ever experienced breathlessness and chest tightness at the same time when at work?

Does the symptom disappear at weekends, when off or on leave?

9. Have you ever, even when not having a cold or flu had sneezing or nose itching at work?

10. Have you ever, even when not having a cold or flu had running nose at work?

11. Have you ever, even when not having a cold or flu had nose blockage at work?

\section{OCCUPATIONAL EXPOSURE HISTORY}

1) Employment:

i) Number of years employed in this occupation

ii) Position-job title:

2) Area of work.

a) Power plants 
b) office

c) others pls specify

3) Duration of work a day

Safety measures while at work (pls tick appropriately)

\begin{tabular}{|c|c|c|c|c|}
\hline & & every time & sometimes & never \\
\hline 1 & Use of the respiratory protective device & & & \\
\hline 2 & Use of hand gloves & & & \\
\hline 3 & Use of goggles & & & \\
\hline 4 & Use of protective gown & & & \\
\hline
\end{tabular}

\section{FAMILY HISTORY}

Were either of your natural parents ever told by a doctor that they had any of the following health conditions: Tick the most appropriate

\begin{tabular}{llllll}
\hline Condition & \multicolumn{2}{c}{ Father } & \multicolumn{2}{l}{ Mother } \\
\hline Yes & No & Don't know & Yes & No & Don't know \\
\hline
\end{tabular}

Hypertension

Tuberculosis

Stroke

Chronic bronchitis(inflammation of bronchi)

Emphysema (enlargement and damage of air sacs)

Asthma

Lung cancer

Other chest conditions 